\title{
Effects of fructose consumption on postprandial TAG: an update on systematic reviews with meta-analysis
}

\author{
Rodrigo C. O. Macedo*, Alexandra F. Vieira, Cesar E. J. Moritz and Alvaro Reischak-Oliveira \\ Grupo de Estudos em Fisiologia e Bioquímica do Exercicio (GEFEX), Universidade Federal do Rio Grande do Sul (UFRGS), \\ Porto Alegre, RS, 90960-200, Brazil
}

(Submitted 20 November 2017 - Final revision received 30 April 2018 - Accepted 7 May 2018 - First published online 2 July 2018)

\begin{abstract}
The aim of this study was to re-examine the chronic effect ( $>7 \mathrm{~d}$ ) of fructose consumption on postprandial TAG, in adolescents and adults. The research was carried out in March 2017 and used different electronic databases, such as Medline ${ }^{\circledR}$ (Pubmed ${ }^{\circledR}$ ), Embase ${ }^{\circledR}$ and Cochrane. The review considered clinical trials (parallel or crossed) that evaluated the effect of fructose consumption for a period longer than $7 \mathrm{~d}$, in humans. Two investigators independently performed data extraction. The outcome was the absolute delta of TAG concentration in a 4-h postprandial period. The results were presented with delta mean difference between treatments with $95 \%$ CI. The calculations were made based on random-effect models. Statistical heterogeneity of treatment effects between studies was assessed by Cochrane's 'Q Test' and ' $I^{2}$ ' inconsistency test. The meta-analysis of the twelve selected interventions ( $n$ 318) showed that fructose generated larger variation $(\delta)$ of TAG concentrations during the postprandial period, compared with other carbohydrates (mean difference: 8.02 (95\% CI 0.46, 15.58) mg/dl (0.09 (95\% CI 0.01, $\left.0 \cdot 18) \mathrm{mmol} / \mathrm{l}) ; I^{2}: 74 \%\right)$. High heterogeneity was generated almost exclusively by one study, and its withdrawal did not alter the result. We concluded that chronic consumption of fructose $(>7 \mathrm{~d})$ has a negative role on postprandial TAG in healthy adolescents and adults, as well as in overweight/obese individuals, but not in diabetics.
\end{abstract}

Key words: Fructose: Postprandial lipaemia: Sugar: Fat metabolism: Meta-analyses

Postprandial lipaemia (PPL) is a complex and dynamic process that involves alteration of lipids and lipoproteins after one or more meals $^{(1)}$. Since 1947 , it has been suggested that PPL plays an atherogenic role ${ }^{(2)}$ and, consequently, is related to the pathogenesis of $\mathrm{CVD}^{(3-7)}$. Exaggerated elevation of TAG in the postprandial period represents an abnormal response from the metabolism and is associated with increased morbidity and mortality $^{(8,9)}$ owing to reduced sensitivity to insulin ${ }^{(10)}$ and endothelial dysfunction by increasing oxidative stress ${ }^{(11)}$.

Several diet factors, such as sugar-rich meals, can worsen postprandial hypertriacylglycerolaemic response ${ }^{(5,12-14)}$. Among these, fructose stands out. Several studies have shown the effect of fructose-rich diets on postprandial TAG increase (15,16) $^{- \text {dose- }}$ related for quantities above $50 \mathrm{~g} / \mathrm{d}^{(17)}$. The mechanisms seem to be associated with the stimulation of liver lipogenesis ${ }^{(14,18)}$, reduction of sensitivity to insulin ${ }^{(18,19)}$ and secretion or reduction of VLDL-TAG clearance ${ }^{(20)}$. For this connection with the increase of atherogenic lipids and lipoproteins, it was suggested that fructose has an indirect role in increased CVD risk ${ }^{(8)}$.

The effects of fructose consumption on fasting ${ }^{(17,21,22)}$ and postprandial TAG (in acute and chronic forms) have been previously analysed by some systematic reviews with metaanalysis $^{(17,23,24)}$. Two of these studies ${ }^{(21,24)}$ presented important conflicts of interest declared by investigators arising from funding by the food industry and showed negative effects only when it contributes to excess of energy in the diet. Therefore, the aim of this study was to re-examine the chronic effect $(>7 \mathrm{~d}$ ) fructose consumption has on TAG during postprandial period, in adolescents and adults.

\section{Methods}

The entire process used in this study was elaborated in accordance with the guidelines presented in Preferred Reporting Items for Systematic Reviews and Meta-Analyses ${ }^{(25,26)}$. This review was registered at http://www.crd.york.ac.uk/prospero as CRD42017059987.

\section{Eligibility criteria}

The review considered studies in humans, such as clinical trials (parallel or cross-over designs) that evaluated the effect of fructose consumption (dissolved in liquid or added to some food and preparation) over a period of $>7 \mathrm{~d}$. The intervention should be compared with any other carbohydrate that does not contain fructose in the chemical composition, and there is no requirement for energy balance between the comparisons. Research was not limited by illnesses or exercise. The effect of fructose consumption on the postprandial TAG concentration 
was evaluated by comparing it with another carbohydrate (fructose-free) in hyperenergetic or isoenergetic conditions. Studies evaluating acute intervention were discarded. In cases of studies with several publications, only one was included.

\section{Research strategy}

The search was carried out in March 2017 and used different electronic databases such as Medline ${ }^{\circledR}\left(\right.$ Pubmed $\left.^{\circledR}\right)$, Embase ${ }^{\circledR}$ and Cochrane, and manual from the references of studies included. The research was composed of and associated with the following terms (and their respective related terms): 'fructose', 'triglycerides', 'hyperlipidemia'. To expand the research, there was no delimitation of type or year of the study. Studies were limited to English, Portuguese and Spanish languages. Research strategy is detailed and available as online Supplementary Material.

\section{Selection of studies}

Two investigators (A. F. V. and C. E. J. M.) assessed titles and abstracts independently from all studies found during the research. Whenever the abstract did not provide sufficient information about inclusion and exclusion criteria, the full article was evaluated. Thereafter, the full study was evaluated and selected by the reviewers independently. The selection of studies was based on previously adopted eligibility criteria. Disagreements were settled by consensus, and in the case of continuing disagreement the evaluation was made by a third investigator (R. C. O. M.). Sampling duplication criteria was controlled by screening the period and place of recruitment, and authors were contacted for clarification when necessary.

\section{Data extraction}

Standardised form using the software Microsoft Office Excel ${ }^{\circledR}$ was adopted for proper data extraction, executed independently by two reviewers (A. F. V. and C. E. J. M.). The main features of the studies selected, such as author, year of publication, population and sample, methods, intervention, outcome and results, were written in detail. Eventual disagreements were settled by consensus by a third investigator (R. C. O. M.). Missing data were requested to the corresponding author of the study. In case of no answer, denying provision or data loss, the study was excluded. For data that were presented only graphically, the results were extracted using DigitizeIt ${ }^{\circledR}$ software (I. Bormann). The studies in which the comparison was not made with carbohydrates and/or acute intervention $(<7 \mathrm{~d})$, as well as those using intravenous carbohydrate infusion, were excluded.

The outcome was the absolute delta of TAG concentration in a 4 -h postprandial period. The deltas were calculated from peak values ( $4 \mathrm{~h}$ ) and basal values (immediately before breakfast) for properly representing the postprandial TAG curve ${ }^{(6,27-29)}$. Values in $\mathrm{mmol} / \mathrm{l}$ were transformed to $\mathrm{mg} / \mathrm{dl}$, multiplying by 88.5 . Standard $\delta$ deviation was imputed by the equation proposed by Higgins \& Green ${ }^{(31)}$.

Studies with two or more comparison or intervention groups within the same sample were included only once. When the study presented more than one comparison component (another carbohydrate) for the intervention (fructose), the data were extracted only by the following priority: starch $>$ glucose.

\section{Evaluation of bias risk}

Evaluation of the methodological quality of the studies included proper randomisation generation, allocation concealment, blinding participants and/or therapist, blinding the assessors of outcomes and description of losses and exclusions, as proposed by Cochrane ${ }^{(31)}$. When these characteristics were described in the published document, it was considered that criteria were met and that they were satisfied and classified as 'low risk' and otherwise as 'high risk'. The studies that did not describe these data were classified as 'unclear risk'. Two reviewers (A. F. V. and C. E. J. M.) carried out quality assessment independently.

\section{Data analysis}

The results were presented with mean $\delta$ differences among treatments with $95 \% \mathrm{CI}$. Mean difference expresses the difference of the intervention effect, when outcome values are standardised. The calculations were made based on randomeffect models. Statistic treatment effect heterogeneity between studies was evaluated by Cochrane's ' $Q$ ' test and ' $I$ ', inconsistency test, where it was considered that values higher than $50 \%$ indicated high heterogeneity ${ }^{(32)}$. Meta-analysis included comparison of fructose consumption with any other carbohydrate (without fructose in composition) on the variation of postprandial TAG (expressed by the delta values) immediately before breakfast ( 0 ) and at the 4-h peak. The value of $\alpha \leq 0 \cdot 05$ was considered statistically significant.

The following sensitivity analyses were carried out: funding source, randomisation, energy balance, form of the carbohydrate provided, type of comparison (comparator), time of intervention (follow-up), amount of carbohydrate provided and length of analysis. The analysis of period $>12 \mathrm{~h}$ was also performed by the $4-h$ data extraction, because not all studies showed the peak values in longer periods. The use of values other than the delta peak (in this case $>12 \mathrm{~h}$ ) would create a confounding factor by the use of another way to measure intervention $v$. control effect. Subdivision by amounts larger or smaller than $87 \mathrm{~g}$ was based in the 95th percentile of fructose consumption (p95) by the American population ${ }^{(33)}$. The software Review Manager version 5.3 (Cochrane Collaboration) was used.

Furthermore, the funnel plot of the variable analysed was carried out to verify the bias of publication. Asymmetry was tested by the Begg and Egger test, being considered meaningful when $P<0 \cdot 10$. The trim-and-fill test was used to estimate the publication's bias effects in interpreting results. The software comprehensive meta-analysis version 2.0 was used.

\section{Results}

Research results

A total of 3337 studies were identified as eligible in the database search. After duplicates were removed, there were 2805 studies 


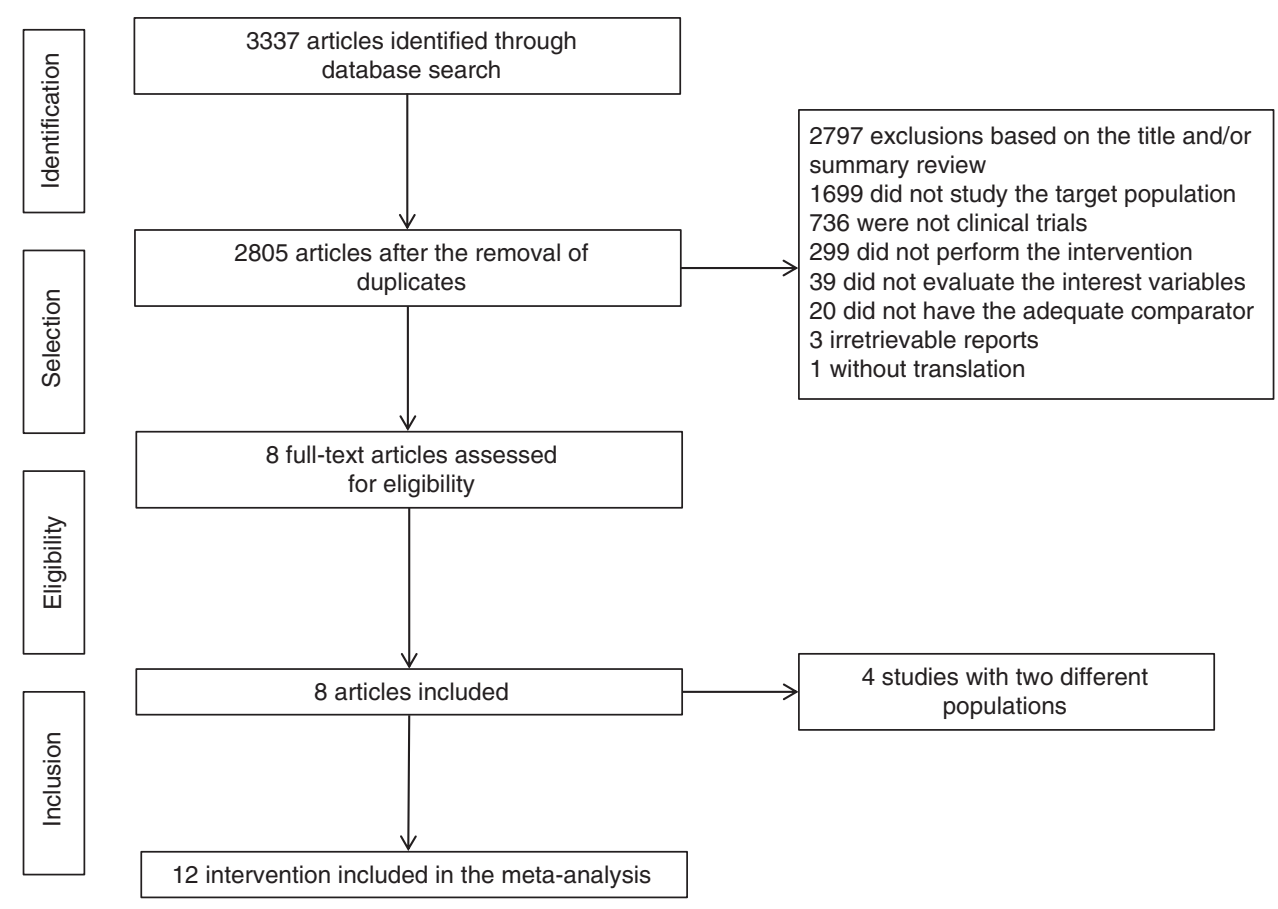

Fig. 1. Flow chart of studies included.

remaining. Of these, it was determined that 2797 were irrelevant based on title and/or summary review, and there were eight studies left. After integral reading, eight studies ${ }^{(18,34-40)}$ and twelve interest interventions (Fig. 1) were included.

\section{Description of the studies}

The complete description of the studies is included in Table 1. Of the twelve interventions selected, five were with healthy individuals $(41.6 \%)^{(35,37,39,40)}$, four with diabetics $(33 \cdot 3 \%)^{(34,36)}$ and three with overweight/obese individuals $(25 \%)^{(38-40)}$. A total of 318 participants were included in this meta-analysis, of whom 148 were men (46.6\%) and 170 were women (53.4\%), with a mean age of 31 years (variation, 17-64 years).

Among the interventions selected, most were carried out in a cross-over ( $83.3 \%)$ and randomised (75\%) design, and exclusively in an environment external to the laboratory (41.6\%). In most interventions, all foods and drinks of the diet were supplied $(75 \%)$. The mean period of intervention was $28 \mathrm{~d}$ (variation, 8-70 d).

The amount of fructose provided in the studies had a mean of $92.6 \mathrm{~g}$ (variation, $50-182 \mathrm{~g}$ ) or $20 \%$ of the total energy of the diet (variation, 10-25\%), mainly provided in a mixed form (solid and liquid) (58.3\%). Studies containing fructose in the comparison component's composition, such as sucrose and maize syrup rich in fructose, were not selected. Thus, $50 \%$ of the interventions used glucose and $50 \%$ used starch as comparison components. The amount of fat at breakfast (the main meal analysed) had a variation of $30-40 \%$ (or $10 \cdot 6-34 \cdot 7 \mathrm{~g}$ ) of the total energy of the meal.

The participants' diets were mainly composed of $55 \%$ carbohydrates, $15 \%$ proteins and $30 \%$ fats ( $83.3 \%)$. The energy balance was estimated as neutral (eight interventions) and positive (two interventions). Two interventions had distinct periods (positive and neutral), but were not separated because they have equal amounts of energy and macronutrients between the intervention and the comparator.

The most common analysis period for the referred variable, postprandial TAG, was $4 \mathrm{~h}(41.6 \%)$. This measure was chosen, primarily, for most studies presenting peak value of this measure and because it provides a good evaluation of lipaemic curve and is a simple protocol that can be used for clinical purpose $^{(6,27-29)}$.

Funding source was extracted and detailed from interventions, wherein $41.6 \%$ were detailed, which could generate conflict of interest and alter the outcome of the study ${ }^{(41,42)}$. Data were extracted as agency or agency/industry funding.

\section{Risk of bias}

Among the studies included, $75 \%$ showed proper randomisation, $16.6 \%$ reported allocation concealment, $33.3 \%$ had blinded the participants and investigators, $16.6 \%$ had blinded the assessors to the outcomes and $33.3 \%$ reported description of sample losses (Fig. 2 and 3).

\section{Postprandial TAG}

Compared with other carbohydrates (starch or glucose), fructose generated higher variation (delta) on the concentration of TAG in the postprandial period, evaluated in $4 \mathrm{~h}$ (mean difference: $8.02(95 \%$ CI 0.46, 15.58) mg/dl (0.09 (95\% CI 0.01, 0.18) $\left.\mathrm{mmol} / \mathrm{l}) ; I^{2}: 74 \%\right)$. The high heterogeneity found $(P<0.0001)$ was almost exclusively generated by one study ${ }^{(39)}$. Its exclusion did not alter the total result of the meta-analysis (Fig. 4). There was no difference in publication bias analysis (Egger's regression, $P=0 \cdot 128$; online Supplementary Fig. S1). 


\section{N British Journal of Nutrition}

Table 1. Characteristics of included studies

(Mean values and standard deviations)

\begin{tabular}{|c|c|c|c|c|c|c|c|c|c|}
\hline \multirow[b]{2}{*}{ Studies } & \multirow[b]{2}{*}{ Subjects } & \multicolumn{2}{|c|}{ Age (years) } & \multirow[b]{2}{*}{ Place of intervention } & \multirow[b]{2}{*}{ Study design } & \multirow{2}{*}{$\begin{array}{l}\text { Control of } \\
\text { consumption* }\end{array}$} & \multirow[b]{2}{*}{ Randomisation } & & \\
\hline & & Mean & SD & & & & & & \\
\hline \multicolumn{10}{|l|}{ Obese/overweight } \\
\hline Stanhope et al. ${ }^{(18)} \dagger$ & $32(16 \mathrm{M}, 16 \mathrm{~W})$ & $\begin{array}{l}53(\mathrm{sD} 10)(\mathrm{M}) \\
54(\mathrm{sD} 5 \cdot 6)(\mathrm{W})\end{array}$ & & Ext/Lab & Parallel & $\begin{array}{l}\text { Dietetic (Lab) } \\
\text { Supplementation } \\
\text { (External) }\end{array}$ & No & & \\
\hline Swarbrick et al. ${ }^{(38)}$ & $7(0 M, 7 W)$ & 64 & 7.9 & $\mathrm{Lab}$ & Crossed & Dietetic & No & & \\
\hline Heden et al. ${ }^{(40)} \ddagger$ & $20(11 \mathrm{M}, 9 \mathrm{~W})$ & $\begin{array}{l}17(\mathrm{SD} 0.5)(\mathrm{M}) \\
17(\mathrm{SD} 0.6)(\mathrm{W})\end{array}$ & & Ext & Crossed & Dietetic & Yes & & \\
\hline \multicolumn{10}{|l|}{ Healthy } \\
\hline Bantle et al. ${ }^{(35)} \ddagger$ & $12 \mathrm{~W}$ & $\begin{array}{l}29 \text { (sD 7.3) (<40 years) } \\
51 \text { (SD 4.9) (>40 years) }\end{array}$ & & Ext & Crossed & Dietetic & Yes & & \\
\hline Bantle et al. ${ }^{(35)} \ddagger$ & $12 \mathrm{H}$ & $\begin{array}{l}31 \text { (SD 7.3) (<40 years) } \\
54 \text { (sD 9.8) (>40 years) }\end{array}$ & & Ext & Crossed & Dietetic & Yes & & \\
\hline Stanhope et al. ${ }^{(39)} \dagger$ & $32(18 \mathrm{M}, 14 \mathrm{~W})$ & 27 & $7 \cdot 0$ & Ext/Lab & Parallel & $\begin{array}{l}\text { Dietetic (Lab) } \\
\text { Supplementation } \\
\text { (External) }\end{array}$ & No & & \\
\hline Swanson et al. (37) & $14(7 \mathrm{H}, 7 \mathrm{M})$ & 34 & $19-60$ & Ext & Crossed & Dietetic & Yes & & \\
\hline Heden et $a l^{(40)} \ddagger$ & $20(9 M, 11 W)$ & $\begin{array}{l}18(\mathrm{sD} 0.6)(\mathrm{M}) \\
18(\mathrm{SD} 0.4)(\mathrm{W})\end{array}$ & & Ext & Crossed & Supplementation & Yes & & \\
\hline \multicolumn{10}{|l|}{ Diabetics } \\
\hline Bantle et al. ${ }^{(34)}$ & $12 \mathrm{DM} 1(6 \mathrm{H}, 6 \mathrm{M})$ & 23 & $15-32$ & Lab & Crossed & Dietetic & Yes & & \\
\hline Bantle et al. & $12 \mathrm{DM} 2(5 \mathrm{H}, 7 \mathrm{M})$ & 62 & $36-80$ & $\mathrm{Lab}$ & Crossed & Dietetic & Yes & & \\
\hline Bantle et al. ${ }^{(36)}$ & 6 DM1 (3M, 3W) & 23 & $18-34$ & Ext/Lab & Crossed & Dietetic & Yes & & \\
\hline \multirow[t]{3}{*}{ Bantle et al. ${ }^{(36)}$} & $12 \mathrm{DM} 2(4 \mathrm{M}, 8 \mathrm{~W})$ & 62 & $40-72$ & Ext/Lab & Crossed & Dietetic & Yes & & \\
\hline & \multicolumn{2}{|c|}{ Dose of fructose§ } & & & & & & & \\
\hline & g & $\%$ & $\begin{array}{c}\text { Form of } \\
\text { consumptionll }\end{array}$ & $\begin{array}{l}\text { Comparison } \\
\text { component } t\end{array}$ & $\begin{array}{l}\text { Intervention } \\
\text { period (d) }\end{array}$ & Diet $^{\star \star}$ & $\begin{array}{l}\text { Energetic } \\
\text { balancet† }\end{array}$ & $\begin{array}{l}\text { Analysis } \\
\text { period }(\mathrm{h})\end{array}$ & Financial support \\
\hline \multicolumn{10}{|l|}{ Obese/overweight } \\
\hline Stanhope et al. ${ }^{(18)}$ & $\sim 182$ & $\geq 25$ & Liquid & Glucose & 70 & $55: 15: 30$ & Neutral/positive & 24 & Agency \\
\hline Swarbrick et al. ${ }^{(38)}$ & $\sim 125$ & 25 & Liquid & Starch & 70 & $55: 15: 30$ & Neutral & 14 & Agency \\
\hline Heden et al. ${ }^{(40)}$ & 50 & 10 & Liquid & Glucose & 15 & $50: 16: 34$ & Positive & 12 & Agency \\
\hline \multicolumn{10}{|l|}{ Healthy } \\
\hline Bantle et al. ${ }^{(35)}$ & 70 & 14 & Mixed & Glucose & 42 & $55: 15: 30$ & Neutral & 24 & Agency \\
\hline Bantle et al. ${ }^{(35)}$ & 70 & 14 & Mixed & Glucose & 42 & $55: 15: 30$ & Neutral & 24 & Agency \\
\hline Stanhope et al. ${ }^{(39)}$ & $\sim 145$ & 25 & Liquid & Glucose & 15 & $55: 15: 30$ & Neutral/positive & 24 & Agency \\
\hline Swanson et al. ${ }^{(37)}$ & 100 & 20 & Mixed & Starch & 28 & $55: 15: 30$ & Neutral & 4 & Agency/industry \\
\hline Heden et al. ${ }^{(40)}$ & 50 & 10 & Liquid & Glucose & 15 & $50: 16: 34$ & Positive & 12 & Agency \\
\hline \multicolumn{10}{|l|}{ Diabetics } \\
\hline Bantle et al. ${ }^{(35)}$ & 85.25 & 21 & Mixed & Starch & 8 & $55: 15: 30$ & Neutral & 4 & Agency/industry \\
\hline Bantle et al. ${ }^{(35)}$ & $85 \cdot 25$ & 21 & Mixed & Starch & 8 & $55: 15: 30$ & Neutral & 4 & Agency/industry \\
\hline Bantle et al. & 100 & 20 & Mixed & Starch & 28 & $55: 15: 30$ & Neutral & 4 & Agency/industry \\
\hline Bantle et al. ${ }^{(36)}$ & 100 & 20 & Mixed & Starch & 28 & $55: 15: 30$ & Neutral & 4 & Agency/industry \\
\hline
\end{tabular}

M, men; W, women; Ext, external to the laboratory; Lab, laboratory; DM1, type 1 diabetes; DM2, type 2 diabetes.

Consumption control: dietetic, when all foods, beverages and supplements were provided. Supplementation, when only the intervention carbohydrate was provided by the investigator.

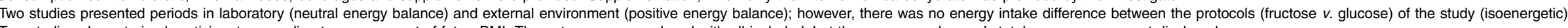

included, but the group or subgroup's total mean age was not disclosed.

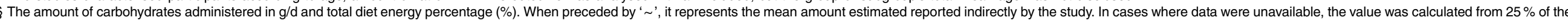
Frlo a diet $8368 \mathrm{~kJ}(2000 \mathrm{kcal})$.

.

Il Comparison component refers to another carbohydrate (control) provided with the intervention (fructose), regardless of whether or not it is hyperenergetic.

utrients' energy values for carbohydrates: proteins: fats informed in the study.

tt Represents the ratio between participants' energy consumption and output. Positive when there was energy surplus. Neutral when both were considered equivalent. 


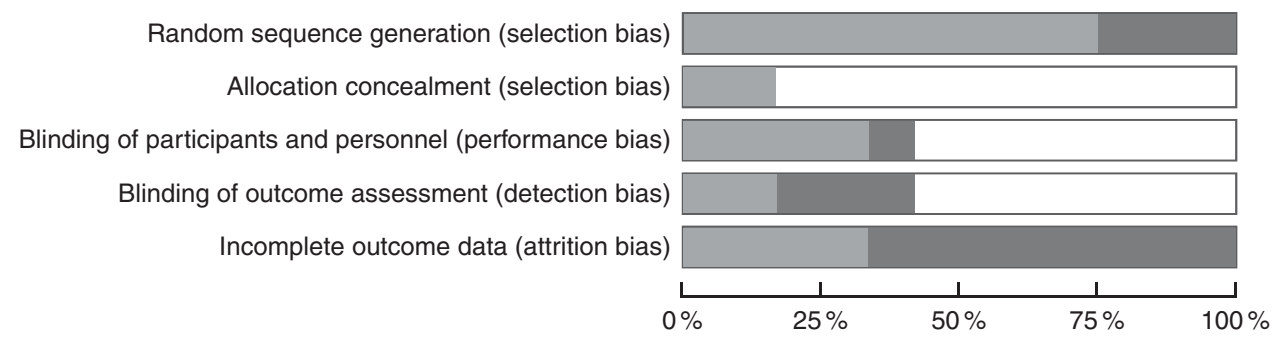

Fig. 2. Risk of bias of the studies included (percentage). $\square$, Low risk of bias; $\square$, unclear risk of bias; $\square$, high risk of bias.

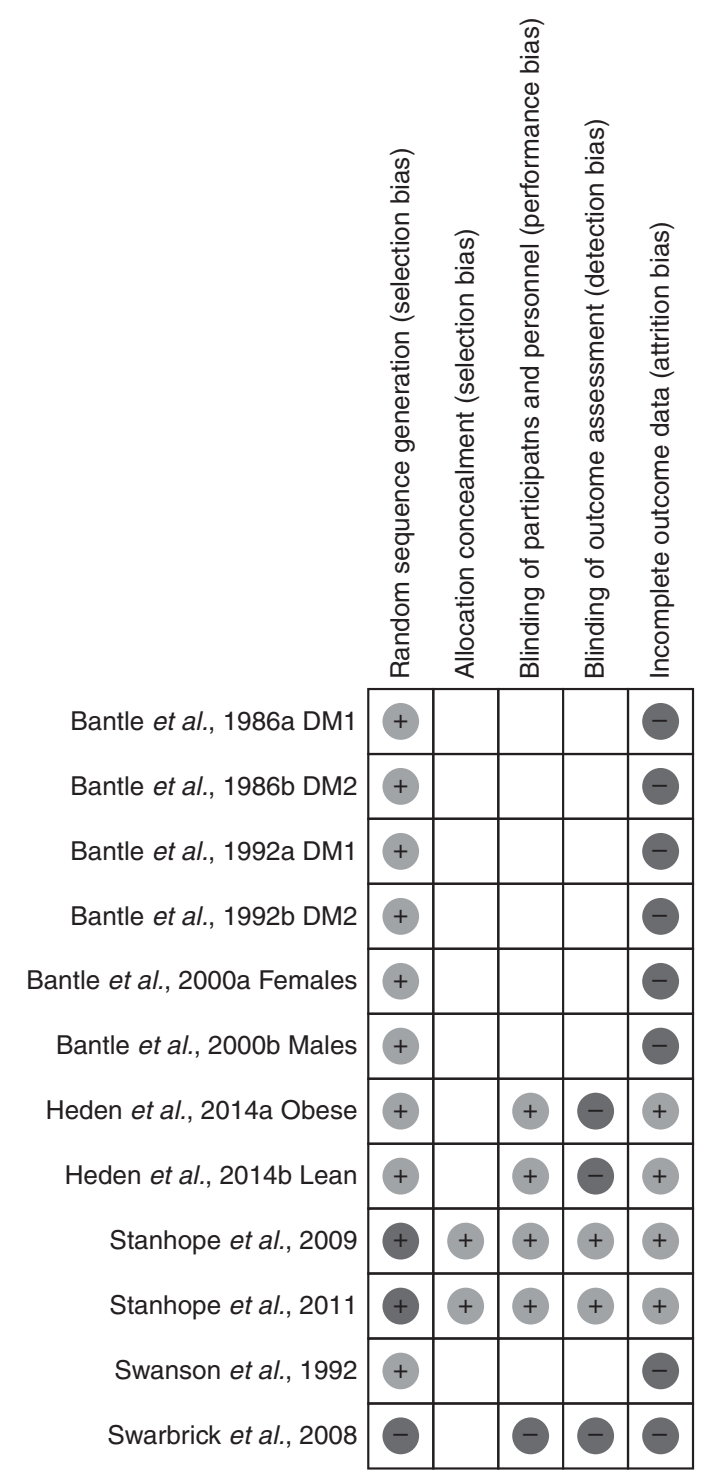

Fig. 3. Summary of risk of bias of the studies included. DM1, type 1 diabetes; DM2, type 2 diabetes.

The analysis of subgroups showed higher variation of TAG concentration for overweight/obese individuals (mean difference: 11.47 (95\% CI 4.51, 18.44) mg/dl (0.13 (95\% CI $0.05,0.21) \mathrm{mmol} / \mathrm{l}) ; I^{2}: 0 \%$ ) and healthy individuals (mean difference: 13.55 (95\% CI 1.60, 25.49) mg/dl (0.15 (95\% CI $0.02,0.29) \mathrm{mmol} / \mathrm{l}) ; I^{2}: 76 \%$ ) but not in diabetics (mean difference: -2.77 (95\% CI $-10.54,4.99) \mathrm{mg} / \mathrm{dl}(-0.03$ (95\% CI $-0 \cdot 12$,
0.06) $\mathrm{mmol} / \mathrm{l}) ; I^{2}: 0 \%$ ). High heterogeneity in healthy individuals $(P=0.002)$ was exclusively generated by one study ${ }^{(39)}$. Its withdrawal did not alter the result of the subgroup.

Owing to the high heterogeneity, sensitivity analyses were carried out in the interventions for the following: (a) funding, industry/agency (mean difference: -2.63 (95\% CI -9.86, 4.60) $\mathrm{mg} / \mathrm{dl}(-0.03$ (95\% CI $\left.-0.11,0.05) \mathrm{mmol} / \mathrm{l}) ; P=0.48 ; I^{2}: 0 \%\right)$ and agency (mean difference: $15 \cdot 20$ (95\% CI 7.40, 23.00) $\mathrm{mg} / \mathrm{dl}$ (0.17 (95\% CI 0.08, 0.26) mmol/1); $P=0.0001 ; I^{2}: 65 \%$ ) (online Supplementary Fig. S2); (b) amount of carbohydrate, $<87 \mathrm{~g}$ (mean difference: 6.97 (95\% CI 2.14, 11.80) mg/dl (0.08 (95\% CI $0.02,0.13) \mathrm{mmol} / \mathrm{l}) ; P=0.005 ; I^{2}: 0 \%$ ) and $>87 \mathrm{~g}$ (mean difference: 7.55 (95\% CI $-6.40,21.49) \mathrm{mg} / \mathrm{dl}(0.09$ (95\% CI $-0.07, \quad 0.24) \mathrm{mmol} / \mathrm{l}) ; \quad P=0.29 ; I^{2}: 81 \%$ ) (subdivision by amounts larger or smaller than $87 \mathrm{~g}$ was based in the p95 fructose consumption by the American population) ${ }^{(33)}$ (online Supplementary Fig. S3); (c) randomisation, yes (mean difference: 3.93 (95\% CI -1.42, 9.29) $\mathrm{mg} / \mathrm{dl}(0.04$ (95\% CI $\left.-0 \cdot 02,0 \cdot 10) \mathrm{mmol} / \mathrm{l}) ; P=0 \cdot 26 ; I^{2}: 21 \%\right)$ and no (mean difference: 22.8 (95\% CI 17.96, 27.64) mg/dl (0.26 (95\% CI 0.20, 0.31) mmol/l); $P<0.00001 ; I^{2}: 0 \%$ ) (online Supplementary Fig. S4); (d) energy balance, positive (mean difference: 14.78 (95\% CI 3.94, 25.62) $\mathrm{mg} / \mathrm{dl}(0.17$ (95\% CI 0.04, 0.29) mmol/l); $P=0.008$; $\left.I^{2}: 82 \%\right)$ and neutral (mean difference: $3 \cdot 11(95 \% \mathrm{CI}-4 \cdot 80,11 \cdot 01)$ $\mathrm{mg} / \mathrm{dl}(0 \cdot 04$ (95\% CI $\left.-0.05,0 \cdot 12) \mathrm{mmol} / \mathrm{l}) ; P=0 \cdot 44 ; I^{2}: 36 \%\right)$ (online Supplementary Fig. S5); (e) form of fructose, liquid (mean difference: 14.78 (95\% CI 5.94, 23.62) mg/dl (0.17 (95\% CI $\left.0.07,0.27) \mathrm{mmol} / \mathrm{l}) ; P=0.001 ; I^{2}: 76 \%\right)$ and mixed (mean difference: $-0.42(95 \% \mathrm{CI}-7.58,6.75) \mathrm{mg} / \mathrm{dl}(0.00(95 \% \mathrm{CI}$ $-0.09,0.08) \mathrm{mmol} / \mathrm{l}$ ); $P=0.91 ; I^{2}: 6 \%$ ) (online Supplementary Fig. S6); (f) type of comparison (comparator), starch (mean difference: 1.19 (95\% CI -7.73, 9.51) mg/dl (0.01 (95\% CI -0.09, $0 \cdot 11) \mathrm{mmol} / \mathrm{l}) ; P=0.78 ; I^{2}: 40 \%$ ) and glucose (mean difference: 15.33 (95\% CI 6.02, 24.64) mg/dl (0.17 (95\% CI 0.07, 0.28) mmol/l); $P=0.001 ; I^{2}: 70 \%$ ) (online Supplementary Fig. S7); (g) followup, <30 d (mean difference: $4.92(95 \% \mathrm{CI}-4.41,14.25) \mathrm{mg} / \mathrm{dl}$ (0.06 (95\% CI -0.05, 0.16) mmol/l); $P=0.30 ; I^{2}: 83 \%$ and $>30 \mathrm{~d}$ (mean difference: 16.85 (95\% CI 6.35, 27.34) mg/dl (0.19 (95\% CI $0.07,0.31$ ) $\mathrm{mmol} / \mathrm{l}) ; P=0.002 ; I^{2}: 0 \%$ ) (online Supplementary Fig. S8); (h) length of analysis, $4 \mathrm{~h}$ (mean difference: -2.63 (95\% CI $-9.86,4.60) \mathrm{mg} / \mathrm{dl}(-0.03(95 \% \mathrm{CI}-0.11,0.05) \mathrm{mmol} / \mathrm{l})$; $\left.P=0.48 ; I^{2}: 0 \%\right)$ and $>12 \mathrm{~h}$ (mean difference: $15.20(95 \% \mathrm{CI}$ $7 \cdot 40,23.00) \mathrm{mg} / \mathrm{dl} \quad(0.17 \quad(95 \%$ CI $0.08, \quad 0 \cdot 26) \mathrm{mmol} / \mathrm{l})$; $P=0.0001 ; I^{2}: 65 \%$ ) (online Supplementary Fig. S9).

Apparently, authors or studies that received funding support from the industry had a tendency to show no increase in TAG concentration after fructose consumption. Non-randomised 
Fructose and postprandial TAG

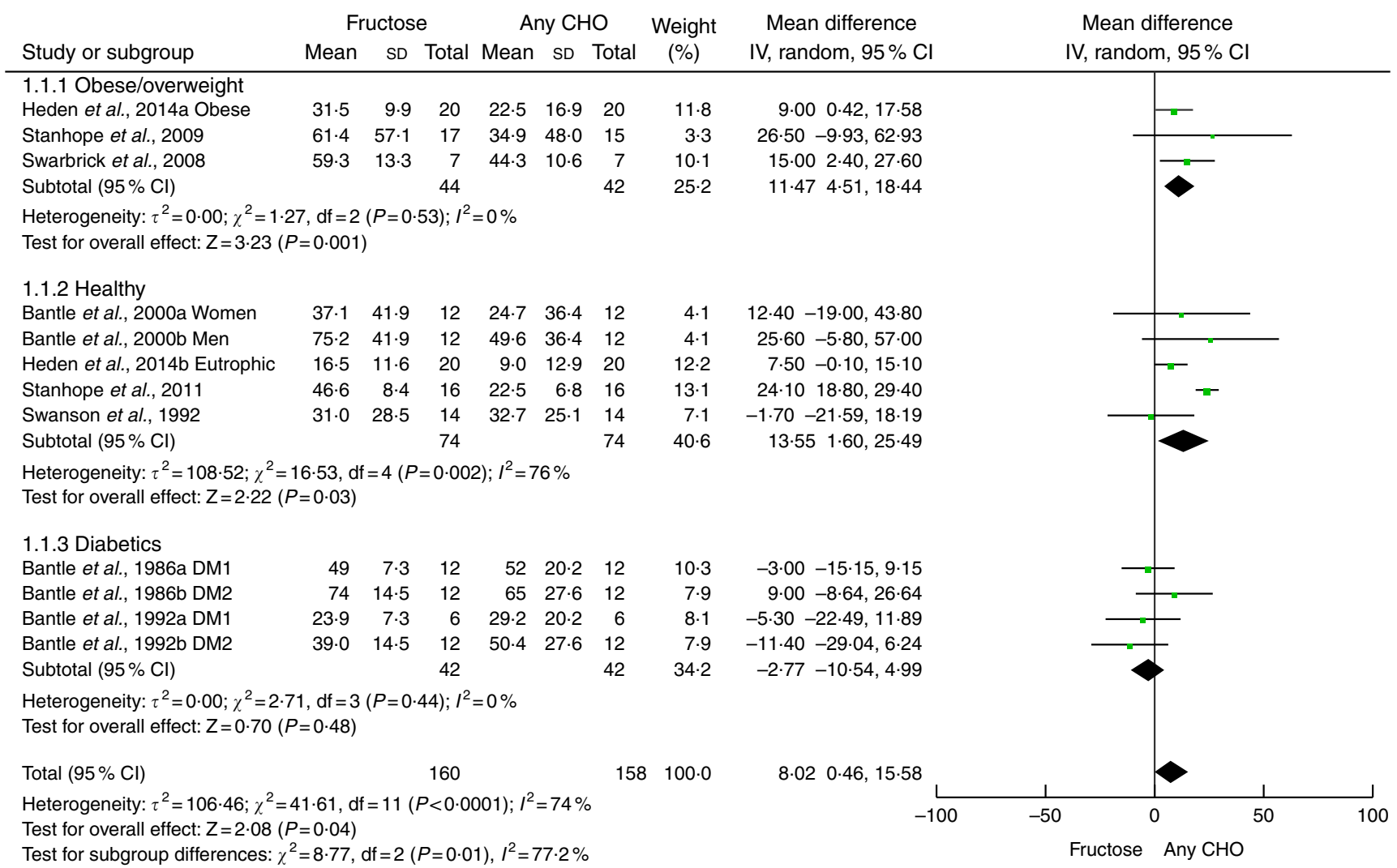

Fig. 4. Forest plot of the effect of fructose or any carbohydrate $(\mathrm{CHO})$ consumption on postprandial TAG in obese/overweight, healthy and diabetic individuals. The estimation for each group (subtotal) and combined effect (total) are detailed. The data are in mean difference and $95 \% \mathrm{Cl}(\mathrm{mg} / \mathrm{dll})$ of the $\delta$ between fasting and 4-h peak TAG. Significance values for the random-effect model. Values in $\mathrm{mg} / \mathrm{dl}$ can be transformed to $\mathrm{mmol} / \mathrm{l}$ by multiplying by 0.0113 . DM, diabetes mellitus.

interventions, positive energy balance, liquid fructose, glucose comparison component, total period of intervention $>30 \mathrm{~d}$ (followup) and length of analysis $>12 \mathrm{~h}$ influenced the results of the study.

\section{Discussion}

The main finding of this systematic review with meta-analysis is that chronic fructose consumption $(>7 \mathrm{~d}$ ) causes higher variation of TAG concentration in the postprandial period when compared with other carbohydrates (glucose or starch). This variation (delta) from fasting (immediately before breakfast) to 4-h peak TAG was about $8.02 \mathrm{mg} / \mathrm{dl}(0.09 \mathrm{mmol} / \mathrm{l})$. This effect occurred in healthy and overweight/obese individuals, but not in diabetics.

Fructose is absorbed in the final portion of the duodenum and ileum, in the small intestine, from non-dependent Na process. From portal circulation, the monosaccharide is transported to the liver, where it can be converted to glucose, lactate, glycogen, glycerol and fatty acids ${ }^{(43-45)}$, regardless of insulin secretion $^{(39)}$. In healthy individuals, fructose is oxidised at approximately $45 \%$, within a period from 3 to $6 \mathrm{~h}$ after ingestion, including the entry of carbons in the lipogenesis pathway ${ }^{(43)}$. The postprandial hyperlipidic effect of fructose seems to originate directly from the synthesis of fatty acids and glycerol in hepatocytes ${ }^{(14,20)}$, and indirectly by the smaller withdrawal of TAG from the plasma by reduction in the activation of lipoprotein lipase from the adipose tissue ${ }^{(20)}$.
Different studies showed that fructose-rich diets induce alterations in the lipid metabolism in eutrophic and overweight/ obese individuals ${ }^{(15,18,39,46)}$. The addition of fructose $(1 \cdot 0-3 \cdot 0 \mathrm{~g} / \mathrm{kg}$ per d) to the diet increases fasting ${ }^{(15,47,48)}$ and postprandial ${ }^{(16,18,39)}$ lipaemia. Moreover, it is associated with the reduction of liver sensitivity to insulin ${ }^{(49)}$, even at moderate doses $(40 \mathrm{~g} / \mathrm{d})^{(19)}$, and decrease of fat oxidation ${ }^{(50)}$.

A series of sensitivity analyses was carried out in order to verify heterogeneity on the results found. One analysis accentuated the relation between industry funding and null results of fructose on postprandial TAG. Clearly, the conflict of interests can interfere in the conclusions of a particular study ${ }^{(42)}$. Currently, the influence of funding by the food industry on several health outcomes has been discussed, as well as how it could modify guidelines of nutrition ${ }^{(41,51,52)}$. Some systematic reviews with meta-analysis have been published on the effects of fructose on blood lipids ${ }^{(17,21,53)}$, glycaemic control on diabetes ${ }^{(54)}$, blood pressure ${ }^{(55)}$, markers of non-alcoholic liver steatosis ${ }^{(56)}$, weight gain $^{(57)}$, uric acid ${ }^{(58)}$ and postprandial $\mathrm{TAG}^{(24)}$. These studies also compared fructose with fructose-containing carbohydrates, including sucrose and high-fructose maize syrup (HFCS), which are more likely to show a small or no effect on different metabolic outcomes ${ }^{(59)}$. Despite the fact that all these studies received funding support from the food industry (which produces or uses fructose in products), results remain feasible but must be interpreted with caution. 
The median amount of fructose among the studies selected was approximately $93 \mathrm{~g}$, which represents approximately $86 \%$ higher than AHA recommendations, but only approximately $7 \%$ above p95 of the consumption by the American population ${ }^{(33)}$. This meta-analysis found that quantities smaller than $87 \mathrm{~g}$ of fructose/d are enough to promote variation in postprandial TAG, as demonstrated in a previous meta-analysis that observed the threshold of $50 \mathrm{~g} / \mathrm{d}$ for the general population ${ }^{(17)}$ and $60 \mathrm{~g} / \mathrm{d}$ for type 2 diabetes ${ }^{(53)}$. These thresholds are very close to the average consumption ( $49 \mathrm{~g}$ ) by the American ${ }^{(33)}$ and Dutch ${ }^{(60)}$ population. However, some authors stated that this effect only occurs when there is positive energy balance or when fructose is generating a hyperenergetic condition in comparison with another carbohydrate $e^{(21,24)}$. This effect was equally found in our study from sensitivity analysis.

The recent meta-analysis by Evans et al. ${ }^{(23)}$ found no difference in postprandial TAG with acute fructose consumption when compared with glucose or sucrose. Furthermore, the authors also propose replacing those sugars for fructose, once they did not find TAG alterations, and glycaemia and insulinaemia reduction were found in the postprandial period. Our view is contrary, as our sensitivity analysis showed that a total time of intervention (follow-up) extended for over $30 \mathrm{~d}$ influenced TAG variation. Although increasingly studied, the effects of chronic fructose consumption are still discordant and are not fully elucidated in the literature because of a number of confounding factors (e.g. fructose dose, excess of energy in the diet, diabetes, obesity) ${ }^{(61)}$.

Some limitations are present in our study. (1) Data showed high heterogeneity; sensitivity analysis demonstrated that this effect was being almost exclusively generated by one study ${ }^{(39)}$ but its removal does not alter the result of subgroups and total results of the meta-analysis. (2) The inclusion of a study with adolescents $^{(40)}$ could create a confusion factor, but it was considered important for representing the metabolic intervention effect on different age groups. (3) One study ${ }^{(38)}$ did not clearly show the amount of fructose provided (in grams or \% of the diet) and, in this case, had to be removed. (4) The amount of fructose varied to a great extent among studies (50-182 g), showing lack of intervention standardisation and often the provision of supraphysiological doses ${ }^{(62)}$. (5) All interventions that evaluated diabetics analysed plasma TAG over a period of $4 \mathrm{~h}$, which may represent a bias; studies with longer analysis periods especially in diabetic subjects are needed. (6) The quality of studies varied between groups, presenting higher risk of bias in diabetes interventions.

Findings from this systematic review with meta-analysis update the results previously described by Wang et al. ${ }^{(24)}$ and showed the negative effects of chronic ( $>7 \mathrm{~d}$ ) fructose consumption on postprandial TAG, in healthy adolescents and adults, as well as in overweight/obese individuals, but not in diabetics. As chronic ingestion of fructose may promote lipaemic alterations, and hypertriacylglycerolaemia in the postprandial period is associated with increased morbimortality, recommendations for the population are needed to limit intake, especially from liquids (e.g. sweetened beverages). Longitudinal studies (>30 d), well-controlled, with habitual doses of consumption between 49 and $87 \mathrm{~g}$ (close to the p95 of the population) and in different forms (free fructose, HFCS, sucrose) are necessary to clarify the interrelationship between fructose, lipaemia and CVD.

\section{Acknowledgements}

The authors thank authors Timothy Daniel Heden, Jill Kanaley and John Sievenpiper for responding our emails and Josianne Krause and Daniel Umpierre for aiding with data analysis.

C. E. J. M. has received PhD scholarship from the Coordenação de Aperfeiçoamento de Pessoal de Nível Superior.

R. C. O. M. formulated the research question; A. F. V. and C. E. J. M. read and extracted data. A. F. V., C. E. J. M., R. C. O. M. analysed the data. R. C. O. M., A. F. V., C. E. J. M. and A. R.-O. wrote, reviewed, performed and perfected this study.

The authors declare that there are no conflicts of interest to declare.

\section{Supplementary material}

For supplementary material/s referred to in this article, please visit https://doi.org/10.1017/S0007114518001538

\section{References}

1. Ooi TC \& Nordestgaard BG (2011) Methods to study postprandial lipemia. Current Vasc Pharmacol 9, 302-308.

2. Moreton JR (1947) Atherosclerosis and alimentary hyperlipemia. Science 106, 190-191.

3. Stefanutti C, Labbadia G \& Athyros VG (2014) Hypertriglyceridaemia, postprandial lipaemia and non-HDL cholesterol. Curr Pharm Des 20, 6238-6248.

4. Lairon D \& Defoort C (2011) Effects of nutrients on postprandial lipemia. Current Vasc Pharmacol 9, 309-312.

5. Lairon D, Lopez-Miranda J \& Williams C (2007) Methodology for studying postprandial lipid metabolism. Eur J Clin Nutr $\mathbf{6 1}$, 1145-1161

6. Kolovou GD, Mikhailidis DP, Kovar J, et al. (2011) Assessment and clinical relevance of non-fasting and postprandial triglycerides: an expert panel statement. Current Vasc Pharmacol 9, 258-270.

7. Mora S, Rifai N, Buring JE, et al. (2008) Fasting compared with nonfasting lipids and apolipoproteins for predicting incident cardiovascular events. Circulation 118, 993-1001.

8. Miller M, Stone NJ, Ballantyne C, et al. (2011) Triglycerides and cardiovascular disease: a scientific statement from the American Heart Association. Circulation 123, 2292-2333.

9. Nordestgaard BG \& Varbo A (2014) Triglycerides and cardiovascular disease. Lancet 384, 626-635.

10. Bansal S, Buring JE, Rifai N, et al. (2007) Fasting compared with nonfasting triglycerides and risk of cardiovascular events in women. JAMA 298, 309-316.

11. Bae JH, Bassenge E, Kim KB, et al. (2001) Postprandial hypertriglyceridemia impairs endothelial function by enhanced oxidant stress. Atherosclerosis 155, 517-523.

12. Cohen JC, Noakes TD \& Benade AJ (1989) Postprandial lipemia and chylomicron clearance in athletes and in sedentary men. Am J Clin Nutr 49, 443-447.

13. Chong MF, Fielding BA \& Frayn KN (2007) Metabolic interaction of dietary sugars and plasma lipids with a focus on mechanisms and de novo lipogenesis. Proc Nutr SoC 66, 52-59. 
14. Parks EJ, Skokan LE, Timlin MT, et al. (2008) Dietary sugars stimulate fatty acid synthesis in adults. J Nutr 138, 1039-1046.

15. Abdel-Sayed A, Binnert C, Le KA, et al. (2008) A high-fructose diet impairs basal and stress-mediated lipid metabolism in healthy male subjects. Br J Nutr 100, 393-399.

16. Bidwell AJ, Fairchild TJ, Redmond J, et al. (2014) Physical activity offsets the negative effects of a high-fructose diet. Med Sci Sports Exerc 46, 2091-2098.

17. Livesey G \& Taylor R (2008) Fructose consumption and consequences for glycation, plasma triacylglycerol, and body weight: meta-analyses and meta-regression models of intervention studies. Am J Clin Nutr 88, 1419-1437.

18. Stanhope KL, Schwarz JM, Keim NL, et al. (2009) Consuming fructose-sweetened, not glucose-sweetened, beverages increases visceral adiposity and lipids and decreases insulin sensitivity in overweight/obese humans. J Clin Invest 119, 1322-1334.

19. Aeberli I, Hochuli M, Gerber PA, et al. (2013) Moderate amounts of fructose consumption impair insulin sensitivity in healthy young men: a randomized controlled trial. Diabetes Care 36, 150-156.

20. Chong MF, Fielding BA \& Frayn KN (2007) Mechanisms for the acute effect of fructose on postprandial lipemia. Am J Clin Nutr 85, 1511-1520.

21. Chiavaroli L, de Souza RJ, Ha V, et al. (2015) Effect of fructose on established lipid targets: a systematic review and meta-analysis of controlled feeding trials. J Am Heart Assoc 4, e001700.

22. Evans RA, Frese M, Romero J, et al. (2017) Chronic fructose substitution for glucose or sucrose in food or beverages has little effect on fasting blood glucose, insulin, or triglycerides: a systematic review and meta-analysis. Am J Clin Nutr 106, 519-529.

23. Evans RA, Frese M, Romero J, et al. (2017) Fructose replacement of glucose or sucrose in food or beverages lowers postprandial glucose and insulin without raising triglycerides: a systematic review and meta-analysis. Am J Clin Nutr 106, 506-518.

24. David Wang D, Sievenpiper JL, de Souza RJ, et al. (2014) Effect of fructose on postprandial triglycerides: a systematic review and meta-analysis of controlled feeding trials. Atherosclerosis 232, 125-133.

25. Liberati A, Altman DG, Tetzlaff J, et al. (2009) The PRISMA statement for reporting systematic reviews and meta-analyses of studies that evaluate health care interventions: explanation and elaboration. Ann Intern Med 151, W65-W94.

26. Shamseer L, Moher D, Clarke M, et al. (2015) Preferred reporting items for systematic review and meta-analysis protocols (PRISMA-P) 2015: elaboration and explanation. BMJ 349, g7647.

27. Kolovou GD, Mikhailidis DP, Nordestgaard BG, et al. (2011) Definition of postprandial lipaemia. Current Vasc Pharmacol 9, 292-301.

28. Mihas C, Kolovou GD, Mikhailidis DP, et al. (2011) Diagnostic value of postprandial triglyceride testing in healthy subjects: a meta-analysis. Current Vasc Pharmacol 9, 271-280.

29. Weiss EP, Fields DA, Mittendorfer B, et al. (2008) Reproducibility of postprandial lipemia tests and validity of an abbreviated 4-hour test. Metabolism 57, 1479-1485.

30. Liberati A, Altman DG, Tetzlaff J, et al. (2009) The PRISMA statement for reporting systematic reviews and meta-analyses of studies that evaluate healthcare interventions: explanation and elaboration. BMJ 339, b2700.

31. Higgins JPT \& Green S (2008) Cochrane Handbook for Systematic Reviews of Interventions, Cochrane Book Series,
Cochrane Collaboration. Chichester; Hoboken, NJ: WileyBlackwell.

32. Higgins JP, Thompson SG, Deeks JJ, et al. (2003) Measuring inconsistency in meta-analyses. BMJ 327, 557-560.

33. Marriott BP, Cole N \& Lee E (2009) National estimates of dietary fructose intake increased from 1977 to 2004 in the United States. J Nutr 139, 1228S-1235S.

34. Bantle JP, Laine DC \& Thomas JW (1986) Metabolic effects of dietary fructose and sucrose in types I and II diabetic subjects. JAMA 256, 3241-3246.

35. Bantle JP, Raatz SK, Thomas W, et al. (2000) Effects of dietary fructose on plasma lipids in healthy subjects. Am J Clin Nutr 72, 1128-1134.

36. Bantle JP, Swanson JE, Thomas W, et al. (1992) Metabolic effects of dietary fructose in diabetic subjects. Diabetes Care 15, 1468-1476.

37. Swanson JE, Laine DC, Thomas W, et al. (1992) Metabolic effects of dietary fructose in healthy subjects. Am J Clin Nutr 55, 851-856.

38. Swarbrick MM, Stanhope KL, Elliott SS, et al. (2008) Consumption of fructose-sweetened beverages for 10 weeks increases postprandial triacylglycerol and apolipoprotein-B concentrations in overweight and obese women. $\mathrm{Br} J \mathrm{Nutr}$ 100, 947-952.

39. Stanhope KL, Bremer AA, Medici V, et al. (2011) Consumption of fructose and high fructose corn syrup increase postprandial triglycerides, LDL-cholesterol, and apolipoprotein-B in young men and women. J Clin Endocrinol Metab 96, E1596-E1605.

40. Heden TD, Liu Y, Park YM, et al. (2014) Moderate amounts of fructose- or glucose-sweetened beverages do not differentially alter metabolic health in male and female adolescents. $\mathrm{Am} \mathrm{J}$ Clin Nutr 100, 796-805.

41. Mozaffarian D (2017) Conflict of interest and the role of the food industry in nutrition research. JAMA 317, 1755-1756.

42. Lundh A, Lexchin J, Mintzes B, et al. (2017) Industry sponsorship and research outcome. Cochrane Database Syst Rev, issue 2, MR000033

43. Sun SZ \& Empie MW (2012) Fructose metabolism in humans what isotopic tracer studies tell us. Nutr Metab (Lond) 9, 89.

44. Elliott SS, Keim NL, Stern JS, et al. (2002) Fructose, weight gain, and the insulin resistance syndrome. Am J Clin Nutr $\mathbf{7 6}$, 911-922.

45. Bray GA, Nielsen SJ \& Popkin BM (2004) Consumption of high-fructose corn syrup in beverages may play a role in the epidemic of obesity. Am J Clin Nutr 79, 537-543.

46. Faeh D, Minehira K, Schwarz JM, et al. (2005) Effect of fructose overfeeding and fish oil administration on hepatic de novo lipogenesis and insulin sensitivity in healthy men. Diabetes 54, 1907-1913.

47. Egli L, Lecoultre V, Theytaz F, et al. (2013) Exercise prevents fructose-induced hypertriglyceridemia in healthy young subjects. Diabetes 62, 2259-2265.

48. Le KA, Faeh D, Stettler R, et al. (2006) A 4-wk high-fructose diet alters lipid metabolism without affecting insulin sensitivity or ectopic lipids in healthy humans. Am J Clin Nutr 84, 1374-1379.

49. Ter Horst KW, Schene MR, Holman R, et al. (2016) Effect of fructose consumption on insulin sensitivity in nondiabetic subjects: a systematic review and meta-analysis of dietintervention trials. Am J Clin Nut 104, 1562-1576.

50. Cox CL, Stanhope KL, Schwarz JM, et al. (2012) Consumption of fructose-sweetened beverages for 10 weeks reduces net fat oxidation and energy expenditure in overweight/obese men and women. Eur J Clin Nutr 66, 201-208. 
51. Bes-Rastrollo M, Schulze MB, Ruiz-Canela M, et al. (2013) Financial conflicts of interest and reporting bias regarding the association between sugar-sweetened beverages and weight gain: a systematic review of systematic reviews. PLoS Med $\mathbf{1 0}$, e1001578; discussion e1001578.

52. Chartres N, Fabbri A \& Bero LA (2016) Association of industry sponsorship with outcomes of nutrition studies: a systematic review and meta-analysis. JAMA Intern Med 176, 1769-1777.

53. Sievenpiper JL, Carleton AJ, Chatha S, et al. (2009) Heterogeneous effects of fructose on blood lipids in individuals with type 2 diabetes: systematic review and meta-analysis of experimental trials in humans. Diabetes Care 32, 1930-1937.

54. Cozma AI, Sievenpiper JL, de Souza RJ, et al. (2012) Effect of fructose on glycemic control in diabetes: a systematic review and meta-analysis of controlled feeding trials. Diabetes Care 35, 1611-1620.

55. Ha V, Sievenpiper JL, de Souza RJ, et al. (2012) Effect of fructose on blood pressure: a systematic review and meta-analysis of controlled feeding trials. Hypertension $\mathbf{5 9}$, 787-795.

56. Chiu S, Sievenpiper JL, de Souza RJ, et al. (2014) Effect of fructose on markers of non-alcoholic fatty liver disease
(NAFLD): a systematic review and meta-analysis of controlled feeding trials. Eur J Clin Nutr 68, 416-423.

57. Sievenpiper JL, de Souza RJ, Mirrahimi A, et al. (2012) Effect of fructose on body weight in controlled feeding trials: a systematic review and meta-analysis. Ann Intern Med 156, 291-304.

58. Wang DD, Sievenpiper JL, de Souza RJ, et al. (2012) The effects of fructose intake on serum uric acid vary among controlled dietary trials. J Nutr 142, 916-923.

59. Stanhope KL, Griffen SC, Bair BR, et al. (2008) Twentyfour-hour endocrine and metabolic profiles following consumption of high-fructose corn syrup-, sucrose-, fructose-, and glucose-sweetened beverages with meals. Am J Clin Nutr 87, 1194-1203.

60. Sluik D, Engelen AI \& Feskens EJ (2015) Fructose consumption in the Netherlands: the Dutch National Food Consumption Survey 2007-2010. Eur J Clin Nutr 69, 475-481.

61. Tappy L \& Le KA (2010) Metabolic effects of fructose and the worldwide increase in obesity. Physiol Rev 90, 23-46.

62. Choo VL \& Sievenpiper JL (2015) The ecologic validity of fructose feeding trials: supraphysiological feeding of fructose in human trials requires careful consideration when drawing conclusions on cardiometabolic risk. Front Nutr 2, 12. 